\title{
Developing Usable Academic Library Website for International Students through Usability Testing
}

\author{
Portia Nyame*, Zhangping Lu, Qiao Fu \\ Institute of Science and Technology Information, Jiangsu University, Zhenjiang, China \\ Email: *portianyame244@yahoo.com
}

How to cite this paper: Nyame, P., Lu, Z.P. and Fu, Q. (2019) Developing Usable Academic Library Website for International Students through Usability Testing. Open Access Library Journal, 6: e5375.

https://doi.org/10.4236/oalib.1105375

Received: April 6, 2019

Accepted: April 26, 2019

Published: April 29, 2019

Copyright $\odot 2019$ by author(s) and Open Access Library Inc.

This work is licensed under the Creative

Commons Attribution International

License (CC BY 4.0).

http://creativecommons.org/licenses/by/4.0/

\section{Open Access}

\begin{abstract}
A usable website is a key to ensuring user satisfaction whiles an unusable website brings about frustration and user dissatisfaction. Usability testing has been identified as a great way to check how usable products are to users. This is however ignored by many designers during the designing stage of products such as websites. This in the long run makes the user experience difficulties, errors, and frustration because the product was not created with the user needs in mind. Usability testing is a great way to explore the needs of users and also identify problems and challenges that users encounter while using a product. Involving users in usability testing helps to produce user-centered websites. This study therefore is an attempt to examine the Jiangsu University English Library Website which was designed for international students. Thus the study seeks to identify the needs of the international students as well as problems the users face whiles using the academic library website by involving them in the usability test. A user evaluation usability test with the Morae software was used in this study to analyze data. The study involves twenty international student participants of whom ten were from Asian Countries outside China and the other ten were from African countries and compared usability issues encountered by the groups when using the JUELW. According to the rule of the thumb 5 users are enough to help explore the usability issues. This study therefore serves as a guide for various libraries to use while conducting usability tests for their users and also makes recommendation for libraries to consider when designing library websites for their users especially international student.
\end{abstract}

\section{Subject Areas}

Information Science, Library, Intelligence and Philology 


\section{Keywords}

Usability Testing, User Centered Design, International Student, Academic Library Websites

\section{Introduction}

Usability testing of library websites has over the years proven to provide testers with data on how useful, effective and efficient these are. Usability testing of library website has continuously revealed problems or facets of library websites that need to be improved or changed to meet the needs of users. There is therefore an increasing need for libraries to frequently examine and improve them for their users.

Library websites have its own distinctive users and even in the same library there may be different users hence the need to conduct user evaluation usability tests that help a library meet the special needs of its own users. It is therefore important for libraries to consider distinctive groups that may exist in a library's population and the special needs, these groups may possess by treating each group independently. Doing these separate group studies during usability testing will help to create user-centered websites that meet the needs of users who are different in one way or the other including class levels, majors, countries and other modes of classification. The kind of classification may differ in various settings but these classifications must be done when they are considered necessary to create user-centered websites for diverse group of users.

Although some scholars have reported that usability can reveal how to make library websites usable for a heterogeneous group of people especially where this groups have varied characteristics, thus, analyses are made generally without considering the various groups independently. This re-echoes the continuous need for user-centered library websites where diverse groups exist. This therefore brought about the increasing need for this research since it intended to help create a greater satisfaction for the varied users by identifying usability issues with the website and solving them to give a greater user satisfaction and an improved website. It will also help highlight similar as well as different user preferences and needs so as to develop user-centric websites.

\section{Background}

In recent years, Chinese universities have seen an influx of international students mostly from Africa and other Asian countries outside China. Jiangsu University for instance has international student population of two thousand students as at March 2018. The students are from 80 different countries with majority of students from African and Asian countries outside China. The English library website was developed to serve international student to help them access library services, resources and key information displayed on the website. To have a better 
understanding of how usable the JUELW was to the international student it served, the Jiangsu University library conducted a usability test which involved twenty international participants of whom ten were from Asian Countries outside China and the other ten were from African countries. The study questionnaire was made up of ten tasks designed to perform. These tasks were designed based on web links; general layout of the website and key information available on the website in order to help identify how meaningful the content was to the different groups. Again, the flexibility and ease with which students could identify and access the information and features on the website were considered.

The goals of study were:

1) To investigate how useful and usable the Jiangsu University Library website was to different groups.

2) Identify and Compare common usage patterns, user needs and preferences of Asian and African students in Jiangsu University.

3) To find out the ease at which users navigate through the website.

4) To identify challenges the two groups encounter when using the website.

\section{Literature Review}

The content, language, structure, design, navigation and accessibility of a library website are important factors to consider when checking for the usability of a library website. [1] These five important parts are mostly considered in checking the usability of library websites. However, researchers have identified the need for creating user-centered library websites which model library websites to reflect the needs of users and hence useful for the users. To make our website useful to our users we adopted a user-centered design.

Creating intuitive, usable and user centered websites has been a major concern to researches. Abras, Maloney-Krichmar, \& Preece described user-centered design as a design process in which end-users impact on how the design takes shape with more emphasis on the importance of user involvement and user needs. [2] Letnikova identified the need for intuitive and usable websites to be created through user-centered activities other than solely from the perspective of librarians. [3] McMullen also asserted that to create intuitive and usable websites there is a need to examine how users interpret links and interact with library websites. [4] To effectively create and model our existing website to be user-centered, website users were asked to perform various tasks using the website so as to know how users interacted with the various sections of our library website.

To create a user-centered website, it is paramount to involve users in usability testing. Winters and Norlin assert that website usability should comprise of end users who when examined in a controlled environment would give the necessary feedback from their point of view during usage. [5] Okhovati, Karami, \& Khajouei emphasised the growing importance of usability studies and attributes it to the fact that library websites are designed for users and hence users must be involved. [6] Other studies therefore conducted in usability test adopted a user-evaluation 
approach to effectively gain users feedback and experiences [7].

Usability testing helps to create user-centered websites. Usability indicates to what extent a website is easy to use, efficient in performing a specific task and satisfactory for end users [8]. Usability studies helps to identify parts of the website that needs to be modified and make useful inputs that enable users to use it effectively without the need for any assistance. The International Standards Organization (ISO) identifies efficiency, effectiveness and satisfaction of users as three important factors to be used when examining the usability of products. [9] To overcome this challenge associated with using library websites, there is the need to frequently examine library websites so as to identify aspects that are problematic. [10] The study however tried to identify and address problems and aspects that need to be modified through usability testing.

Library websites may have different user groups. Kim asserts that different usage patterns exist among different user groups and consequently emphasised the need for considering user differences during library website usage studies [11]. His article therefore categorised the users into undergraduate student, master's student, and doctoral student and faculty members. In another usability study of the University of Southern Mississippi, Azadbakht, Blair, and Jones studied how different groups differ in using the library websites by classifying the user groups-undergraduate students, graduate students, faculty members and library employees to ascertain which parts of the website needed to be remodelled for the users. [12] This spearheaded the need for our usability test considering the fact that our users were from different countries. Our study therefore sought to examine how our users differ in using the website. The Florida International University Libraries also tested three targeted groups consisting of 26 undergraduates, 14 graduate students and 5 faculty members to determine the usability of the top page of their website and made the necessary changes for their users [13].

A usability study at the Hunter's college library by Becker and Yannotta revealed the need to create user-centered website through a combination of usability testing and design process. Their study employed usability testing as an aid in building user-centered websites that not only reflects the needs and preferences of users but also incorporate and alter new technologies and resources when they emerge throughout the design process [14]. Our study therefore tries to identify new technologies and resources that can be incorporated into the websites to assist our users.

In another study Menzi-Çetin, Alemdağ, Tüzün, and Yıldız adopted a think aloud process in its usability test while users performed 11 tasks concerning their university's web pages to ascertain the perceptions of their users [15]. Our study also adopts the think aloud method in the usability study to establish user perceptions, preferences, satisfaction, preference and suggestions.

\section{Methodology}

The Jiangsu University Library organised a usability study with the Tech Smith's 
Morae (version 3.) which recorded the actions of participants, their time on task and the success rates of the participants. The test was conducted in February 2018. The Jiangsu English library Website (JELW) could previously be accessed http://lib.ujs.edu.cn/englib/englib/site/Resources.html (as seen in Figure 1).

This usability test was conducted with the support of the Institute of Technology and Information department of Jiangsu University and international students studying in the library. Five international students who were studying with the library were trained by two expert teachers in the Information Behaviour department of the library for the purpose of this study. The training sessions held outlined the purpose of the usability study, demonstrated how to administer tasks and questions as well as how to record scores and make observations. The teachers supervised as well as reviewed all materials and questionnaires involved in the testing.

An enquiry conducted about international student from the overseas education office showed that, African and Asian Student were highly populated in the school. Participation in this study was voluntary after notices were given to the various departments. Thirty (30) students volunteered and were screened based on their level of education (Masters and $\mathrm{PhD}$ ) in addition to their continent of origin (Africa and Asian countries apart from china). After the screening twenty comprising of ten Africans and ten Asians were selected for the study. This number of participants was considered adequate based on the rule of the thumb (at least five users in a usability study can reveal usability problems) and the need for much heterogeneous user perspective in usability study. ${ }^{16}$ Considering the different countries these student came from, it was necessary to study how usable the university website was to the various groups since its members may have had different website experiences. To help gather a much varied and heterogeneous user perspective about the English library website, we made sure we did not select two international students from the same country. This method also allowed us to have a cross section of countries of the international students.

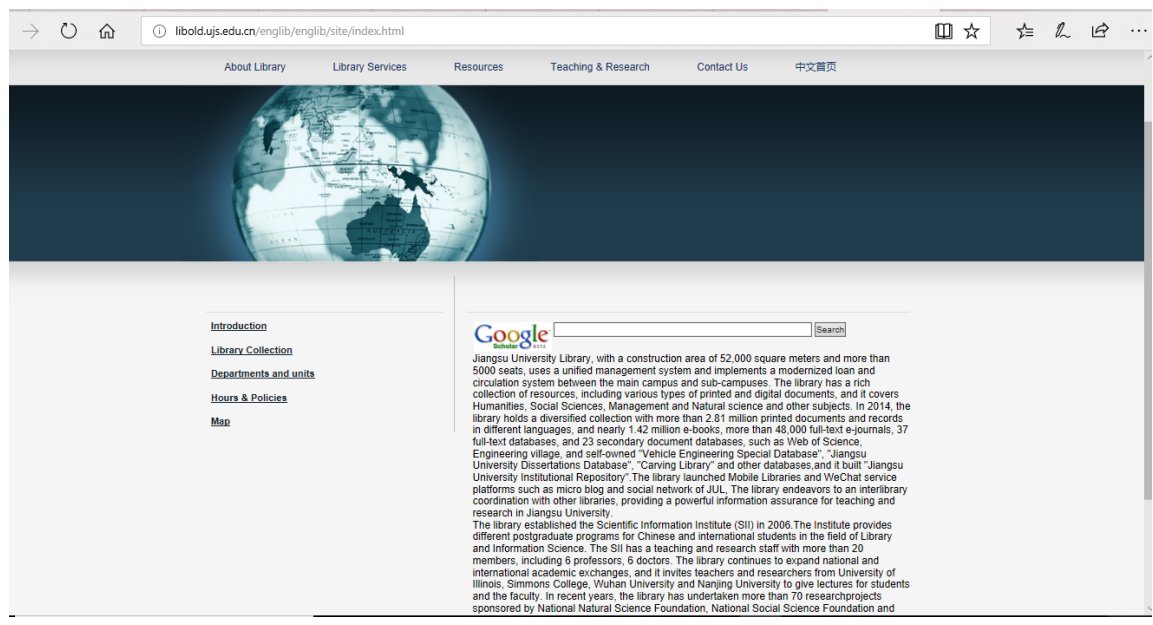

Figure 1. The Jiangsu University English Library Website. 
It also helped to clearly identify the varied views that existed and difficulties associated with using the website by the groups. The background of the different groups can be seen in Table 1 and Table 2 .

The testing was done in the Jiangsu University Library's Information and Behaviour Laboratory (IBL). Participants were well assured of their confidentiality and advised to think aloud whiles completing different tasks. Participants were examined one at a time to allow participants to feel at ease while using the website. The starting point of the usability test was set to the homepage of the English library's website before participant's entered. Each participant took all three parts of the test before leaving the lab. Computers in the lab which have video cameras installed on them were used. One computer had the Morae Recorder installed on it to record participant on-screen activity and actions whiles the

Table 1. Background of Asian Students and Experience with the JUELW.

\begin{tabular}{cccccc}
\hline Participant & Level & $\begin{array}{c}\text { Duration in } \\
\text { school. } \\
\text { (semester) }\end{array}$ & Major & Country & $\begin{array}{c}\text { Used library } \\
\text { website before. } \\
\text { (Yes/No) }\end{array}$ \\
\hline Asian 1 & PHD & 2 & Environmental Science & India & No \\
Asian 2 & PHD & 4 & Finance and Economics & Pakistan & Yes \\
Asian 3 & Masters & 3 & Food Science and Technology & Afghanistan & Yes \\
Asian 4 & Masters & 2 & Civil Engineering & Iran & Yes \\
Asian 5 & Masters & 1 & Mathematics & Russia & No \\
Asian 6 & PHD & 6 & Applied Linguistics & Iraq & Yes \\
Asian 7 & Masters & 2 & Agricultural Engineering & Vietnam & Yes \\
Asian 8 & PHD & 1 & Management & Japan & Yes \\
Asian 9 & PHD & 2 & Civil Engineering & Indonesia & No \\
Asian 10 & PHD & 1 & Business Administration & Bangladish & Yes \\
\hline
\end{tabular}

Table 2. Background of African Students and Experience with the JUELW.

\begin{tabular}{cccccc}
\hline Participant & Level & $\begin{array}{c}\text { Duration in } \\
\text { school. } \\
\text { (semester) }\end{array}$ & Major & Countries & $\begin{array}{c}\text { Used library } \\
\text { website before. } \\
\text { (Yes/No) }\end{array}$ \\
\hline Africa 1 & Masters & 1 & Public Administration & Ghana & No \\
Africa 2 & Masters & 2 & Food Science & Cameroon & No \\
Africa 3 & Masters & 2 & Computer Science & Zimbabwe & Yes \\
Africa 4 & PHD & 2 & Agricultural Engineering & Tanzania & Yes \\
Africa 5 & Masters & 2 & Optical Engineering & Ethiopia & Yes \\
Africa 6 & Masters & 2 & Applied economics & Nigeria & No \\
Africa 7 & Masters & 2 & MBA & Zambia & Yes \\
Africa 8 & PHD & 1 & Management & Sudan & No \\
Africa 9 & Masters & 2 & Mechanical Engineering & Gambia & No \\
Africa 10 & PHD & 1 & Material Science & Senegal & Yes \\
\hline
\end{tabular}


Morae Observer and Morae Manager were installed on another computer to observe, take notes and analyse recordings.

The testing consisted of three parts: pre-test questionnaire, task, post-test questionnaire Questionnaires which also contained outline of the three parts of the test were printed and given to participants. Users were also encouraged to think aloud so as to help identify problems, misconceptions and users opinions they had.

The pre-test questionnaire consisted of ten questions which included the background information of participants, courses offered, experiences of users with the English library website and other academic institution websites used. The pre-test results were used to form comparison groups to get a better understanding of their background information and any differences that existed.

The task consisted of ten questions which included locating the library map, library opening hours, location of different rooms, circulation policies, resources, contact us, library services, departments and the interlibrary loan service (as seen in Appendix 1). One expert teacher upon reviewing the tasks suggested that though the library website helped to access important databases like the Web of Science, Emerald, Science Direct, Swetswise and EI Village, there was however no clear link to return to the homepage after using these library resources. The task 5 was therefore reviewed for the users not to find articles or conduct searches using these databases but rather they were asked to identify three of these databases. Future research would focus on examining users searching skills and how the website meets their needs. The main purpose of these tasks was to assess if they could easily identify the needed information and if the design of the websites met user expectation. Determining the success of completing each task was very important in this study to help identify usability issues faced by participants and how they behaved with the library website. The test sessions were videotaped for later review.

The post-test questionnaire was an attempt to examine the rate at which users were satisfied with the English library website and gain user comments about the website. Participants were given incentives after completing all the three tests.

The research group reviewed the recordings after all participants had performed the task and analysed the results. The Morae usability Manager helped to obtain most of the results and only the post test result and special notes was taken manually. The results of the two user groups was compared and analysed, usability issues was noted and a report of the findings and recommendations were made.

\section{Limitation of Study}

Even though the study sought to include as many international students as possible, the study could not reflect all the international student population. Also, only postgraduate students were considered in this study. Including undergraduate students in the study would have also given us opinions which would 
also have helped to create a user-centered website for all international students despite their academic levels.

\section{Results}

The pre-test questionnaires revealed the various departments and levels of participants. The pre-test questionnaire also revealed that use of the library website by international student was low. Thirty five (35\%) of Asians had used the library website and fifteen percent (15\%) had not used the library website whiles twenty five (25\%) of Africans had used the library website and twenty five (25\%) had not used the library website before (see Figure 2). This indicated that more Asians participants used the library website. It was considered that the postgraduate students used the website more to search for articles and for research purposes and a $90 \%$ use rate was predicted, however, it was found that only $60 \%$ of the users had used the library website.

All participants who had used the website before stated that they had been informed about the JEULW website by their friends and mostly used the website for research purposes. However, they used it when the need arose usually in their offices, dormitories, library and their classrooms at most 5 hours per week. Similar comments made by participants for using and not using the library website includes: "I have not heard about the English Library Website", "I have information needed for my studies", "I use Google and other search engines for my research", "I use different search systems or options available on the internet". Five participants stated that, they had not used the JEULW because they had not heard of its existence. This enlightened us of the need to not only examine the usability of the website but to promote the use of the library website since the website will only be beneficial to users when they know about it and use it.

The pre-test questionnaire showed that seven Africans had used the academic website of their previous universities while only six Asians had used academic websites of previous universities. Even though the number of users did not reflect

\section{Usage of JELW}

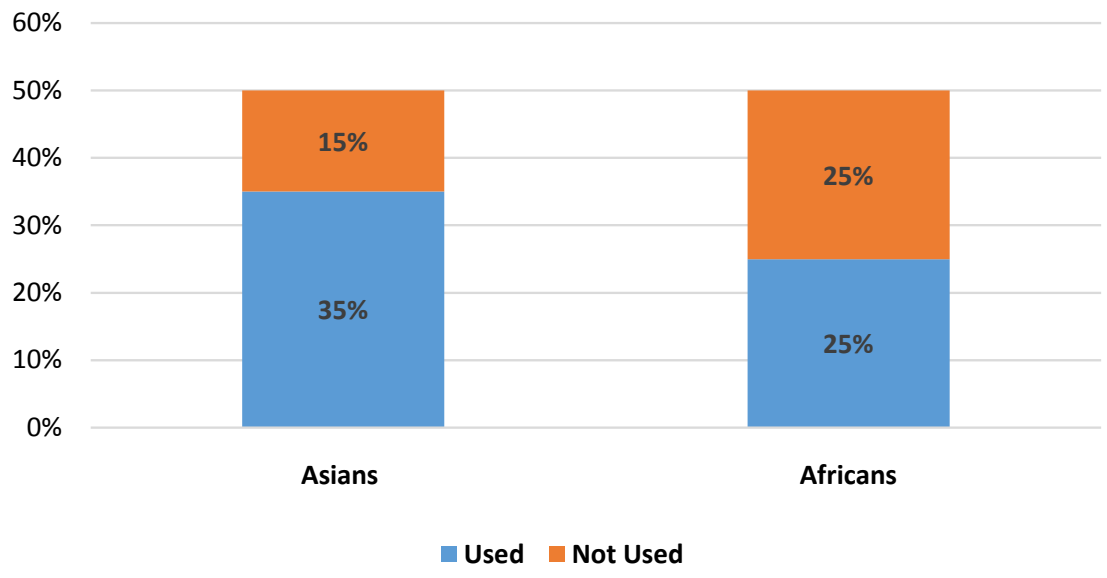

Figure 2. Number of students who have used or not used the JUELW. 
the entire population this information was considered relevant to identify if their usage of previous website affected the use of the JUELW.

The task consisted of ten main questions. Some of the questions contained sub-questions which the participants were expected to complete together with the main questions. Figure 3 indicates the average time spent on each task for the two groups of students while Table 3 shows performance across all tasks and successful completion.

\section{Task}

Each task designed helped to uncover usability problems that were encountered by users whiles using the websites. The task as well as the problems identified during each task is explained below:

Task 1-Locate the Library Map.

Users were expected to locate the library map on the JELW page. This question was to find out if users could identify important features on the website. The average time spent on this task by Africans was 0.60 seconds whiles the Average time spent by Asians on this task was 0.52 seconds indicating that all participants completed this task in the shortest possible time. It was observed that one African participant could not complete the task successfully and one Asian completed task with difficulty however most participants completed with ease. During the think aloud process some observations were made (Table 4).

Task 2-Identify the Library Opening Hours.

Participants were asked to locate the opening hours of the library. This task consisted of two questions. The first was to find the library's opening hours for Saturdays and the second was to identify the library opening hours for the multimedia room. 4 Africans and 3 Asians could not complete the task. Both groups

Table 3. African and Asian Percent Success during the task.

\begin{tabular}{|c|c|c|c|c|c|c|}
\hline & African & & & & Asian & \\
\hline Task & $\begin{array}{c}\text { Time } \\
\text { (Minutes) }\end{array}$ & $\begin{array}{c}\text { Success } \\
\text { (Percentage) }\end{array}$ & $\begin{array}{c}\text { Percentage } \\
\text { Completed with } \\
\text { Difficulty }\end{array}$ & $\begin{array}{c}\text { Time } \\
\text { (Minutes) }\end{array}$ & $\begin{array}{c}\text { Success } \\
\text { (Percentage) }\end{array}$ & $\begin{array}{c}\text { Percentage } \\
\text { Completed } \\
\text { with difficulty }\end{array}$ \\
\hline Task 1 & 0.60 & $90 \%$ & $10 \%$ & 0.52 & $100 \%$ & $10 \%$ \\
\hline Task 2 & 2.64 & $60 \%$ & $30 \%$ & 2.20 & $70 \%$ & $40 \%$ \\
\hline Task 3 & 2.16 & $90 \%$ & $30 \%$ & 2.27 & $90 \%$ & $40 \%$ \\
\hline Task 4 & 1.71 & $70 \%$ & $30 \%$ & 1.35 & $60 \%$ & $20 \%$ \\
\hline Task 5 & 1.70 & $60 \%$ & $20 \%$ & 1.36 & $90 \%$ & $10 \%$ \\
\hline Task 6 & 1.20 & $80 \%$ & $10 \%$ & 0.96 & $70 \%$ & $30 \%$ \\
\hline Task 7 & 1.22 & $20 \%$ & $20 \%$ & 1.00 & $30 \%$ & $20 \%$ \\
\hline Task 8 & 0.84 & $100 \%$ & $10 \%$ & 0.43 & $100 \%$ & $0 \%$ \\
\hline Task 9 & 1.47 & $80 \%$ & $10 \%$ & 1.46 & $70 \%$ & $0 \%$ \\
\hline Task 10 & 1.40 & $80 \%$ & $20 \%$ & 1.31 & $80 \%$ & $30 \%$ \\
\hline
\end{tabular}




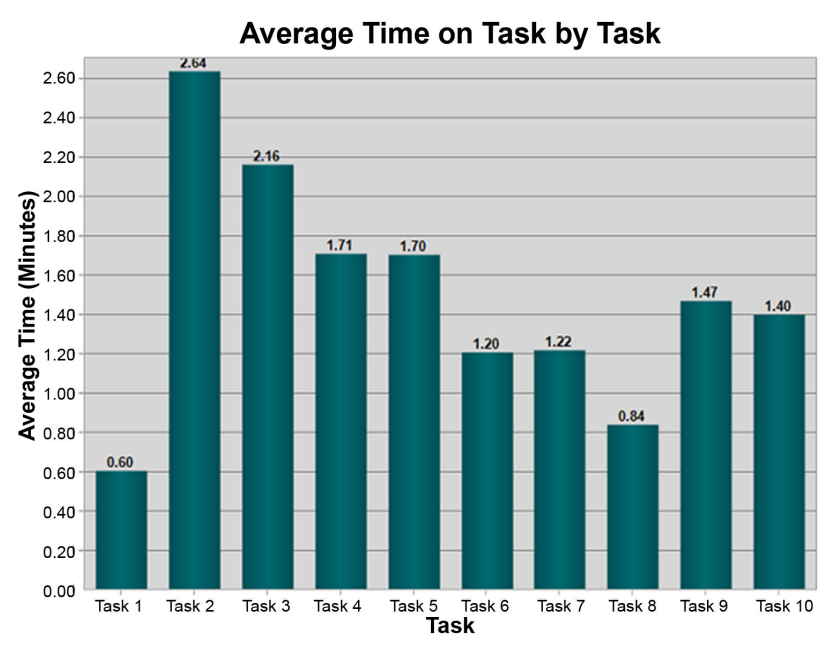

AFRICANS

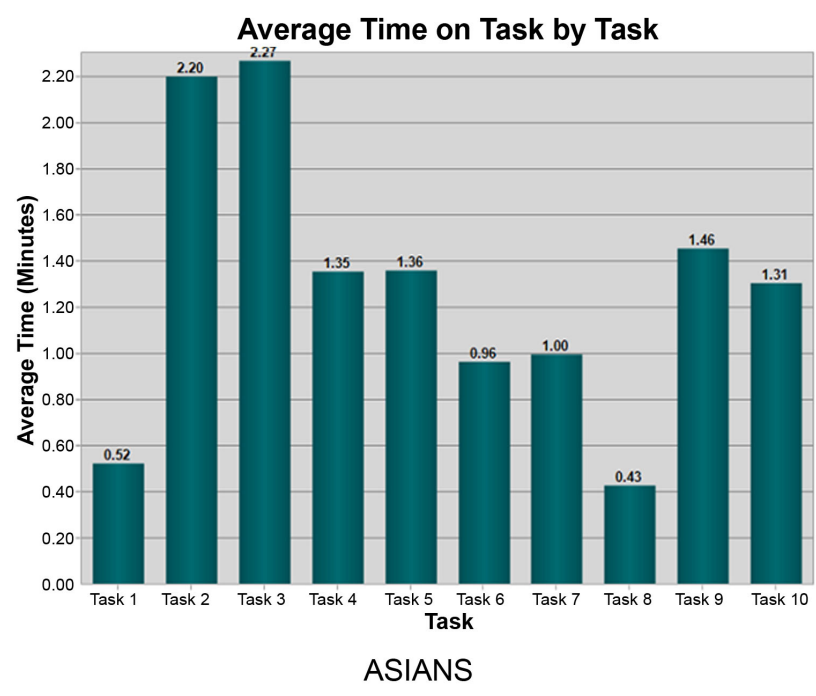

Figure 3. Average time used by each group to complete tasks.

Table 4. Observations and user comments made during task session.

\begin{tabular}{|c|c|c|}
\hline Participants & Comments & Observation \\
\hline Asian & $\begin{array}{l}\text { 1) "I found the website easily but it's in } \\
\text { Chinese and I can't locate the library in case } \\
\text { I am using this map } \\
\text { 2) "Major landmarks around the map should } \\
\text { be indicated in English to help easy location" } \\
\text { 3) "The landmarks on the map should be } \\
\text { translated to English" } \\
\text { 4) I have experienced this interruptions } \\
\text { before and I don't know the cause (the map } \\
\text { could not fully open after the participant } \\
\text { clicked on the map) }\end{array}$ & $\begin{array}{l}\text { 1) The system got interrupted when } \\
\text { three Asians clicked on the "map" the } \\
\text { map could not open } \\
\text { 2) One participant had difficulty and } \\
\text { kept on searching the "library Service } \\
\text { link" for the library map. }\end{array}$ \\
\hline Africans & $\begin{array}{l}\text { 1) "Even though I have seen the map I don't } \\
\text { understand it because it's in Chinese" } \\
\text { 2) I Think this object when clicked should } \\
\text { show the library map because it looks like a } \\
\text { map"(participant saw a map on the page but } \\
\text { it was not the library map) } \\
\text { 3) "This map can't help me locate the library } \\
\text { I can only see the Chinese characters" }\end{array}$ & $\begin{array}{l}\text { 1) One African clicked on the world } \\
\text { map which was displayed on the library } \\
\text { home page and thought it was the } \\
\text { library map } \\
\text { 2) Participants were struggling to locate } \\
\text { the landmarks closer to the library } \\
\text { because it was written in Chinese. }\end{array}$ \\
\hline
\end{tabular}

experienced difficulty in locating the general opening hours of the library however participants completed the sub-task with ease by identifying the library opening hours for the multimedia room because this section displayed the exact time each service was offered. Fifty percent of both Asian and Africans clicked on the "hours and policies" correctly however they got could not easily locate the "library Opening Hours". Three important observations were made 1) participants needed a clear definition of the general library hours 2) participants clicked on "library service" or "hours and policies" to locate the general hours of the library and 3) display of excess information and the clustered nature of the information. It was noted however that participants needed a clear description of 
the general library opening hours, display of relevant information and "drop-down menu" for easy display of what the main links like "hours and policies" entailed.

Task 3-Find the location of the library sections

Participants were asked to complete two questions under this task. First they were asked to locate the floor which the western language book circulation section was located and secondly they were asked to locate the Jiangsu University collected works room. Participants used the "hours and policies" link whiles others used "library collection" link. Here, 5 Asians and 6 Africans found it easy to complete. Just as some participants got frustrated when searching for the floor on which the multimedia room was located in the first task, some participants were equally frustrated because they assumed it was similar to this task hence they did not complete the task. Navigation problems were recorded during this session. For the second part of this task participants were asked to locate the Jiangsu University collected works room. Some participant did not even attempt to answer this question and stated that since the first question was similar it will be difficult to complete the task. Others when encouraged to give it a try found both the main task and the sub task even though they completed it with some difficulty. Figure 4 shows how the tasks were completed with ease, with difficulty or the user failed to complete the task.

Task 4-Identify the Circulation Policies

Participants were expected to identify some circulation policies in the library. This was done to ascertain their ability to get information on borrowing books if they needed. Participants were asked to point out the circulation policies governing the number of books a graduate student can borrow. Even though the term encompassed a lot it was restricted to borrowing of books in this study. When participants were asked to complete this task, they encountered various problems with 4 Asians completing the task easily, 2 completed with difficulty
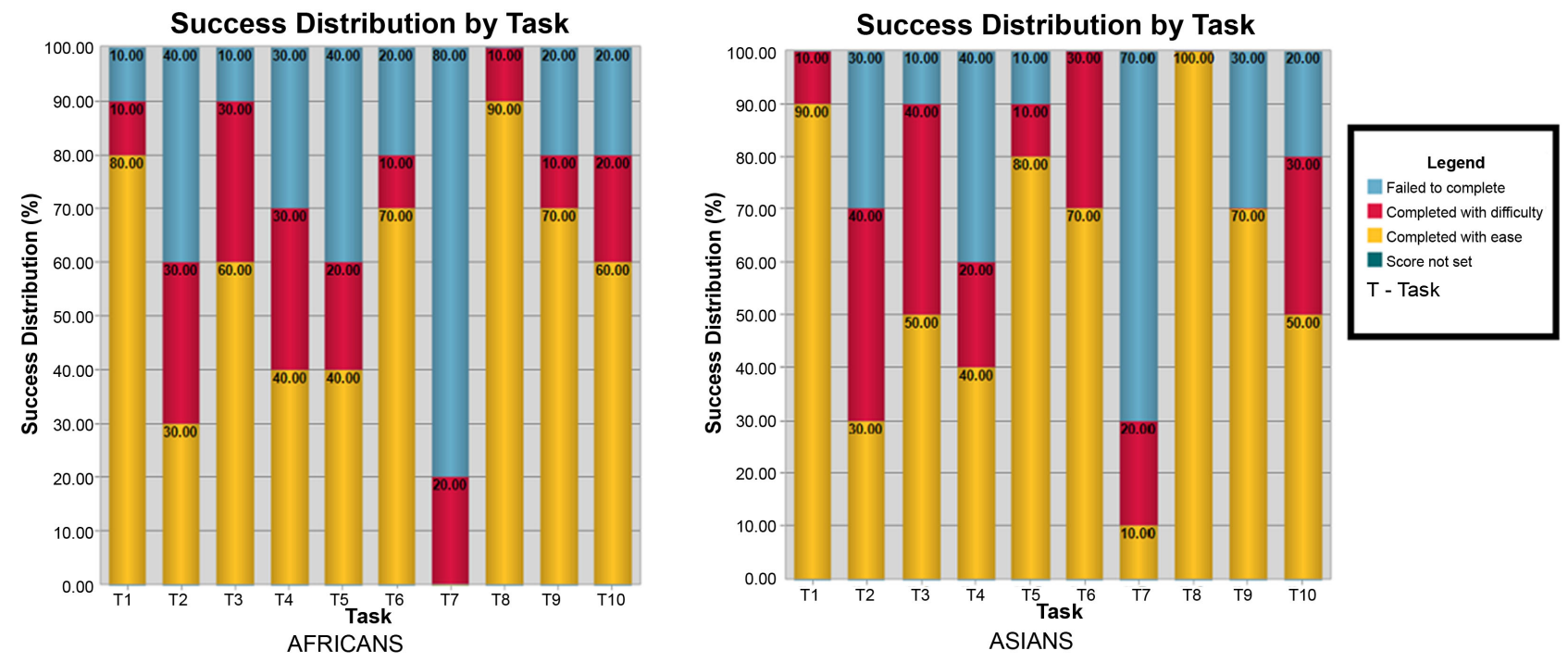

Figure 4. Rate of success of completing each task. 
and 4 could not complete the task. Four Africans completed with ease, 3 completed with difficulty and 3 could not complete the task. It was realised that even though some participants clicked on the "hours and policies link" rightly, they could not complete the task. Three important points were noted here 1) some participants after scanning through the page saw lots of information displayed on the page and got frustrated while searching 2) some participants were disappointed after they clicked the "hours and policies link", they expected to find only two links, namely "Hours" (to specify the hours) and "Policies" (to describe the policies governing borrowing a book) so they can click on the policies to find any information they wanted on the policies and 3)participants complained about the scattered nature of information and the need for a clear display of information. They were however not satisfied with the page and most of them could not complete the task.

Task 5-library Resources

Participants were asked to locate some databases using the library website. The majority of Asians (8) completed the task with ease while only 4 Africans completed with ease. It was observed that $50 \%$ of all participants could not complete the task. Asians tended to complete this task with ease due to the fact that most of the Asians were familiar with the website and also stated that the term "Resources" was understandable for them. On the other hand African participants who failed to identify the resources stated that they had not used the website before and also the term "Resources" did not meet their expectation. They then suggested that the term "Resources" which contained the databases on the website must be modified. It was observed that participants who found it difficult to locate the databases opted to use the "Google Search Option" but this was not functional.

Task 6-Locating the Chinese Homepage

A link on the website led to the Chinese Homepage. This link was named “中 文首页” on the JUELW and served as a link to Chinese homepage (see Figure 5). This also contained important databases like the CADAL database which was not found on the English website. The goal of this test was to identify whether the user will effectively identify the use of this link. The aim of this task was not to examine the usability of the Chinese library website but to examine how effectively the users would use the link “中文首页” on the English library website. Only one participant (African) could not complete the task successfully; all other participants completed successfully mainly by guessing as the think-aloud process revealed. Important observations that were made on both groups included:

- Some users did not click “中文首页” on the English library website to link up with the Chinese website. They typed in the Chinese website address and used it.

- Some participants said they had to guess what the link was before they clicked on the link since the link was written in Chinese characters.

- There was a need to review the link “中文首页” to “Chinese Homepage”. 


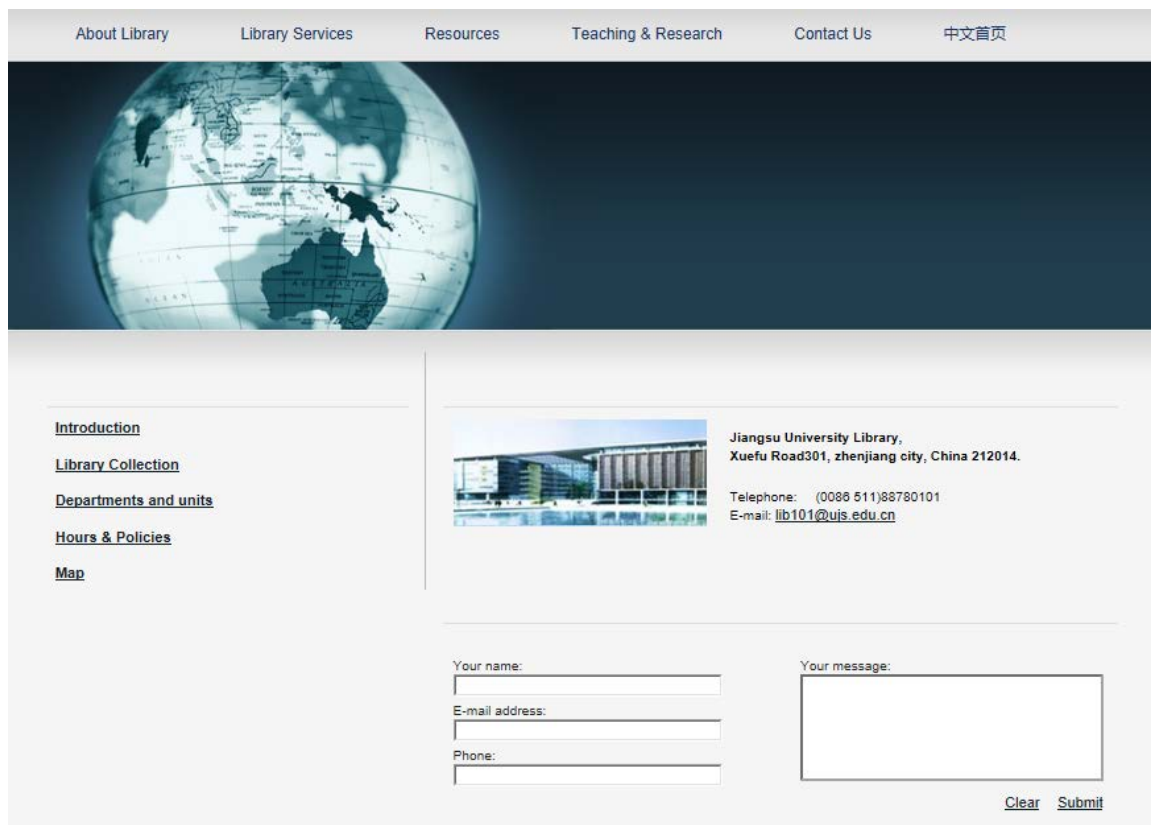

Figure 5. English Library's “Contact Us Page”.

- One participant suggested the need for drop down notes to help them identify which link to use.

However it was observed that $90 \%$ of the participants found the CADAL database easily and navigated with ease back to the English library website with ease.

Task 7-Contacting a Librarian

Library help services are of great importance in every library. It was therefore important to check if users could easily access the details of a librarian when the need arises for some enquiries. (See Figure 5 for "contact us page"). Only 1 Asian and 2 Africans completed with ease. This means that 17 participants either completed the task with difficulty or could not complete the task at all. Participants were asked to identify the details of a librarian. It was realised that $70 \%$ clicked on "contact us" to find the details of a librarian but only realised that it contained the main library's phone number and email address. This however made most participants give up on the search. Others complained that they had used this site previously but did not get any response and hence they did not want to use this function. Others clicked on "departments and unit" and gave details of the various department and offices instead of the details of a librarian. They did not notice that these were not details of librarians. It was realised that, $90 \%$ were not satisfied with this task as was judged by their actions and comments. One participant commented on the need for online chat options. One participant claimed that she wanted to see the names of librarians on the "contact us" page. This was common problem found across both groups.

Task 8-Identifying Library Services

Participants were asked to identify three library services. This task was very useful because it helped identify how the users would find the information about 
the various services the library offered. All participants successfully clicked the library services as the first move. It was however not difficult for them to identify the library services. Comments users made during this task include:

- They identified other services which they did not know about.

- The information was scattered on the page.

Task 9-Research and Teaching Staff

There is a team in the library responsible for helping students conduct research. Participants were asked to identify one research teacher responsible for research in patents and an article which the teacher had written. Eight Africans and seven Asians completed task successfully. It was easy for most participant to identify the research and teaching stuff but others who could not find this information tried to use the topic they were interested in to find the teachers they would need in their research work and hence did not find the teachers and the courses that were available.

Task 10-Interlibrary Loan Services

The interlibrary loan services allow users to borrow books from other institutions hence it was treated separately from the other services. This disclosed the details to help users borrow books from other institution hence this task was considered as very crucial. This service was considered separately because of the different users involved and it was assumed that this service was very useful to them.

Eight Africans and eight Asians successfully completed the task. Two participants could not complete because even though they found the library services link they did not scan through the information to find the interlibrary loan service. Two participants exclaimed they could not find the interlibrary loan service which means that they were trying to locate this link independently. Also the information on this page was scattered and did not make it easy to find the "interlibrary loan page". Both groups commented on the font size of the writing on the page; it was very small and was not clear to them (see Figure 6 for an illustration of this page).

\section{Discussions and Recommendations}

The Jiangsu University Library serves different users and these include the Chinese students, International students and the faculty of Jiangsu University. The Jiangsu University English Website was designed specifically for International students. This paper therefore sought to study user behaviour and usability issues associated with the website by the different user groups that make up International students at Jiangsu University.

The usability test revealed that the library provided a virtual "entrance" into the library because the results indicated that only two students came to the library to access the library website. Most users accessed the library website from remote places and this included classrooms, offices and dormitories. It was also revealed that $40 \%$ of the participants had not used the library website because 


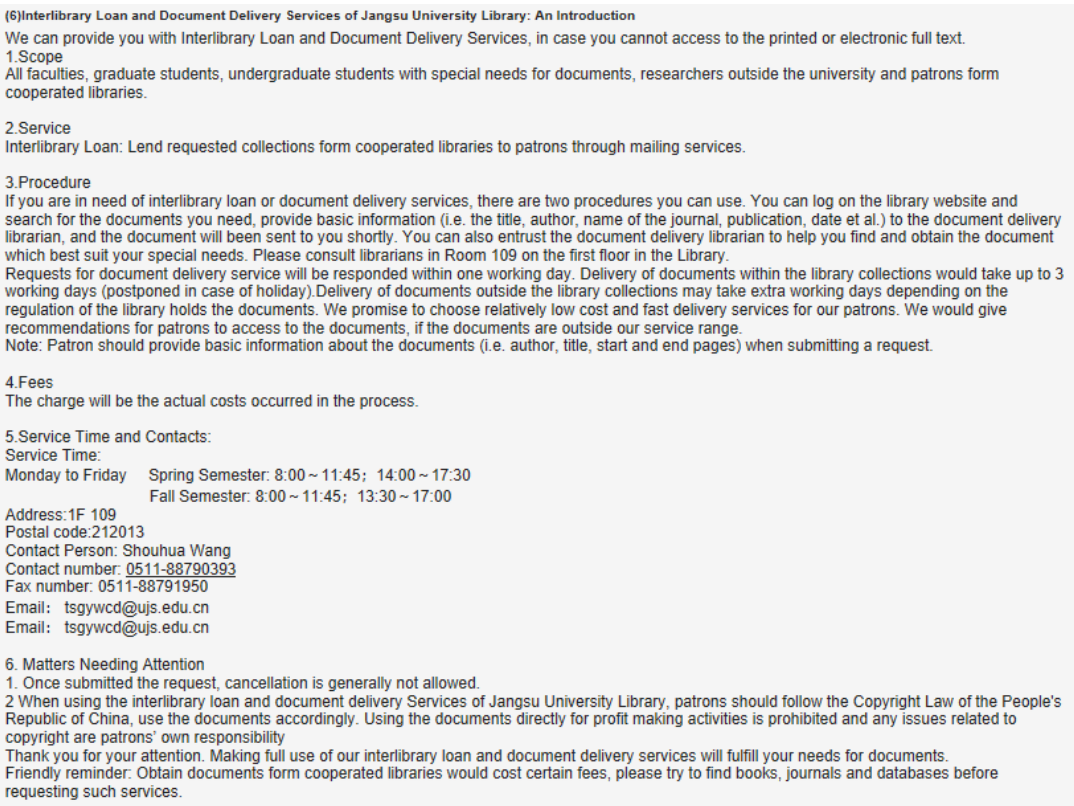

Figure 6. Small font size and clustered nature of information about the interlibrary loan service.

they had no knowledge about the website. This revealed the need to promote awareness of the library website as well as library services and resources to the international students to enhance use of the website. Users who had previously used the website could not identify that the library website performed other important functions and were unaware about other possible functions the library website had to offer. It was also noted that even though the library website contained important features like providing online based services, location of different floors in the library, circulation policies and assistance from librarian, the users mainly knew about the website's ability to help them access various databases. This was not due to lack of knowledge about the use of a library's website as it was noted that $60 \%$ of both group of users had used their former university's website. They sought for information they needed most.

The test revealed that diverse group of users will bring to light broader usability issues. This was evident in the differing user time on task, the rate of success of completing each task, the path of locating items and the comments made by the different groups and suggestions given in answering the post-test questionnaire. Also, the study allowed for a cross-section analysis between the two groups. A cross-sectional study helps to bring to light different and broader needs and usability issues. The usability issues identified were used to improve the library website for the varied groups that existed in Jiangsu University.

The testing of the Jiangsu University English Library Website (JUELW) brought to light some usability issues and aspects that needed to be improved upon. The study revealed that the content of the website was clustered and this did not allow for easy navigation. Task 2, Task 5 and Task 7 showed that the pages were poorly organised and hence difficult to locate information. There was 
a need to summarise, reorganise and sift out important information on the pages. Although the website interface displayed all the important content, users could not adequately recognise this information because of improper design layout and clustered nature of the information. This however made some users frustrated when they spent a long time on tasks. Interestingly most users claimed that they could not complete some tasks because they had not used the system before. It was noted that a user-centered website must be intuitive and usable to first time users.

The arrangement of information on the website was also inconsistent and some important links were not functional. It was observed that the Google search engine was not functional. Users who tried to use it spent long hours waiting for the search to begin. It was also noted that, the link that led to the Chinese website was written in Chinese (中文首页) this needed to be changed to help users access the website without guessing as the users could only identify by guessing. Also, it was recommended that landmarks on the map should be written in English and not Chinese for the benefit of the users. Where users had to guess the contents of some headings drop-down menus were recommended which will highlight what the headings entailed.

The team together with the experts made some important recommendations to the administration. Comments, observations and results indicated the need to create a user-centered library website for these different users. The recommendations was made based on comments, observation, differing rate of completion of tasks, time spent on task and results that were recorded from both groups. The recommendations were used in a later design of a new website for international student. Recommendations that were made included: 1) Clear display of "library opening hours" 2) The need for an "Online Library Catalog" on the website 3) Functional "search engines" 4) The need for "Drop-down menu" and change of “中文首页” 5) Detailed “Contact us” 6) The need to integrate new technologies on the website and 7) creation of the "Events and Products" option.

There was the need for "Clear opening hours" of the library. Participants when asked to find the library opening hours for Saturday were not sure of the information to give. Most stated that even though the different services and department had different times of operation for Saturday, they were not sure of the time of operation for Saturdays. A clear display of library opening hours is needed on the library website. This study shares the same view since the users commented on the need for the library's opening hours to be displayed separately from that of the ones displayed at the service session.

The study also recommended the need for an "online library catalog" on the webpage. This will allow users to effectively locate books and other library materials available in the library. From a previous survey conducted about international student and library usage in Jiangsu University, it was revealed that international students could not use the "Online Public Access Catalog" that was installed on the library computers because it was in Chinese. The website was therefore considered as an option to help international student access the OPAC 
in English. This will therefore allow for easy search of information by using author, title, subject/keyword or date to easily search for necessary information.

There was also the need for a functional "Search Engine". The current search engine titled "Google Scholar" on the website was not functional. Users tried to use this search engine when they could not find what they needed on the website however, this section was unresponsive. There was however the need for a new search engine that will link the users directly to the contents of the library website. This would help the different users to find what they need in the shortest possible time taking into consideration the different time taken on each task by each group.

Moreover there was the need for "Drop-Down Menu". In most tasks the users had to click different headings trying to identify what they needed. It was observed that drop-down menus will meet this need of the users. This will display adequate information about the link and users can easily identify what they need in the case that the different users have different perceptions of a link. There was also the need to change the “中文首页” to “Chinese Homepage” because this term would be familiar to the users and users would not have to guess when using this option.

The "Contact us" option did not display important information about how to contact a librarian. The website only had the email and telephone number of the general library. The team recommended the need for a proficient English librarian's number to be displayed on the page to allow for effective communication and timely response to user requests. It was observed that users could not send their requests through "chat option". Some users refused to use this function since they had previously used it and they did not get the expected result. The team however took note of this problem and recommended the need for a functional "chat option" and a special email address for international student to send their request.

Libraries have advanced to integrate more comprehensive tools like discovery tools and lib guides, and are now testing the usability of these web tools by their users. Where library websites have not incorporated these technologies like the index-based discovery systems, it is important for libraries to implement discovery tools in the system to enhance searches and usage of library websites. It was also recommended that the library incorporate lib guides and other Web 2.0 tools. This will enhance the ease of use and allow for social networks to be incorporated on the website. Where these systems do not meet needs of our users, it was also recommended that the library modify these systems through usability testing to suit its users. This will therefore enhance the performance of the library website and provide a powerful user experience for all students.

Lastly, there was the need for the creation of the "News and Products" section. This will help inform the users about the library and events taking place in the library. This will also be a means to advertise library services or products that are of interest to international students. This will enhance library usage of international student in the long run. 
This discussion and recommendations is based on the common and varied information that both groups provided and where the issue was paramount on the part of a group it was clearly stated. This broad view was used to provide recommendations for the library administration to create a new website for the international students. It was also noted that the different background (country) of the users affected their use of the library website and thus if the given recommendations are put in place, there will be effective usage of the website by both groups.

\section{Conclusions}

The results of our usability study re-echo the need for user-centered websites. Each library website has its own unique users hence the need for usability testing to identify needs and preferences for users and create a usable website reflects the needs of the users. User behaviour research helps to examine how users conduct inquiry, retrieve information, browse and utilize information. It also involves other influencing factors in specific situations. The most essential purpose is to improve the accuracy of user access to information and the value of the information utilization on library websites and systems. Usability tests not only examine websites but help to identify user behaviour, needs and preferences.

Two groups (Asians and Africans) were a part of this study and were used as comparison. The study recorded slight differences in the time spent on tasks and the completion of tasks. However, the differences had to do with mode of locating information and the comments made by users. This allowed us to access broad user preferences and make recommendations that will make the website usable for both groups of users. The purpose of the research was not to compare "who completed first" but to examine how usable the JUELW was to both groups and thereby establishing a user-centered website for both groups.

The study revealed that the JUELW did not only need an update but had to be usable for the various groups of users it served since both groups had trouble completing different tasks. The Asians were however familiar with the website because most of the Asians had used the website before and this however reflected in the time of completing each task. The Africans however spent more time on tasks compared to the Asians because most Africans had not used the website before. However, this did not be the basis for Asians completing all tasks with ease. It is important to note that this study is not an attempt to highlight user search patterns but how usable the library website is to the different groups of users it served.

The users who participated in this usability test helped to make recommendations suitable for international students and hence remodelled our website into a user-centered website that reflects needs of the users. Some recommendations were implemented on the new website which can be accessed through http://lib.ujs.edu.cn/en/content.jsp? urltype=tree.TreeTempUrl\&wbtreeid=1164. 
The recommendations made are not only important to Jiangsu University library but should serve as a basis for providing usable website for international students in many different libraries.

\section{Acknowledgements}

This work was part of the Program on "Innovations research on library services" funded under the National Social Science Foundation of China, grant number 16BTQ004. The authors are grateful to all study participants.

\section{Conflicts of Interest}

The authors declare no conflicts of interest regarding the publication of this paper.

\section{References}

[1] Poll, R. (2007) Evaluating the Library Website: Statistics and Quality Measures. World Library and Information Congress. 73rd IFLA General Conference and Council, Durban, South Africa, 19-23 August 2007, 1-9. https://archive.ifla.org/IV/ifla73/papers/074-Poll-en.pdf

[2] Abras, C., Maloney-Krichmar, D. and Preece, J. (2004) User-Centered Design. In: Bainbridge, W., Ed., Encyclopedia of Human-Computer Interaction, Sage Publications, Thousand Oaks, CA, 445-456.

[3] Letnikova, G. (2004) Usability Testing of Academic Library Web Sites: A Selective Annotated Bibliography. Internet Reference Services Quarterly, 8, 53-68. https://doi.org/10.1300/J136v08n04_04

[4] McMullen, S. (2001) Usability Testing in a Library Web Site Redesign Project. Reference Services Review, 29, 7-22. https://doi.org/10.1108/00907320110366732

[5] Winters, C. and Norlin, E. (2002) Usability Testing for Library Web Sites. ALA Editions, Chicago, IL.

[6] Okhovati, M., Karami, F. and Khajouei, R. (2017) Exploring the Usability of the Central Library Websites of Medical Sciences Universities. Journal of Librarianship and Information Science, 49, 246-255. https://doi.org/10.1177/0961000616650932

[7] Garrett, J.J. (2010) The Elements of User Experience: User-Centered Design for the Web and Beyond. Pearson Education, London.

[8] Joo, S., Lin, S. and Lu, K. (2011) A Usability Evaluation Model for Academic Library Websites: Efficiency, Effectiveness and Learnability. Journal of Library and Information Studies, 9, 11-26.

[9] Bevan, N. (2009) Usability. In: Liu, L. and Özsu, M.T., Eds., Encyclopedia of Database Systems, Springer, Boston, MA, 3247-3251. https://doi.org/10.1007/978-0-387-39940-9_441

[10] Trapido, I. (2016) Library Discovery Products: Discovering User Expectations through Failure Analysis. Information Technology and Libraries, 35, 9-26. https://doi.org/10.1016/S0099-1333(01)00180-X

[11] Kim, Y.-M. (2011) Users' Perceptions of University Library Websites: A Unifying View. Library \& Information Science Research, 33, 63-72. https://doi.org/10.1016/j.lisr.2010.04.007

[12] Azadbakht, E., Blair, J. and Jones, L. (2017) Everyone's Invited: A Website Usability 
Study Involving Multiple Library Stakeholders. Information Technology and Libraries, 36, 34-45. https://doi.org/10.6017/ital.v36i4.9959

[13] Hammill, S.J. (2003) Usability Testing at Florida International University Libraries: What We Learned. Electronic Journal of Academic and Special Librarianship, 4, No. 1.

[14] Becker, D.A. and Yannotta, L. (2013) Modeling a Library Website Redesign Process: Developing A User-Centered Website through Usability Testing. Information Technology and Libraries, 32, 6-22. https://doi.org/10.6017/ital.v32i1.2311

[15] Menzi-Çetin, N., Alemdağ, E., Tüzün, H. and Yıldız, M. (2017) Evaluation of a University Website's Usability for Visually Impaired Students. Universal Access in the Information Society, 16, 151-160. https://doi.org/10.1007/s10209-015-0430-3

[16] Fagan, J.C., Mandernach, M., Nelson, C.S., Paulo, J.R. and Saunders, G. (2012) Usability Test Results for a Discovery Tool in an Academic Library. Information Technology and Libraries, 31, 83-112. https://doi.org/10.6017/ital.v31i1.1855 


\section{Appendix}

\begin{tabular}{ll}
\hline \multicolumn{1}{c}{ Pre-Test Questionnaire } & \multicolumn{1}{c}{ Task } \\
\hline 1. Which country do you come from? & 1. Find the library map? \\
2. What is your Level of Education? & 2. a) Identify the library opening hours for \\
(Masters/PHD) & Saturday. \\
& b) Identify the opening hours for multimedia room \\
3. What is your major? & 3. Locate these library floors \\
& a) The western language book circulation room \\
& b) Jiangsu University collected works room
\end{tabular}

4. How long have you been studying in Jiangsu 4. Identify how many books a graduate student can university? borrow

5. Have you used the English library website before?

5. Identify three library databases on the website

6. If yes, where do you access the website?

6. locate the Chinese homepage

7. For what purpose do you usually access the library website

7. identify a contact of a librarian

8. How often do you access the website?

8. identify three library services

8. a. if No, why?

9. locate one research or teaching assistant

9. Did you ever used your previous university's 10. Locate the interlibrary loan service and find academic website in your country?

their time of operation. 